\title{
Kawasaki Disease in a 2-year-old Child with Dengue Fever: Correspondence
}

\author{
Beuy Joob $^{1}$ • Viroj Wiwanitkit ${ }^{2,3,4,5,6}$
}

Received: 9 November 2015 / Accepted: 28 December 2015 / Published online: 25 January 2016

(C) Dr. K C Chaudhuri Foundation 2015

To the Editor: The recent report on "Kawasaki Disease (KD) and Dengue" is very interesting [1]. Jagadeesh et al. noted that "prospective studies would be required to examine whether dengue could be a potential etiological agent of KD" and also mentioned that "our patient did not have thrombocytosis or thrombocytopenia, probably because of the simultaneous occurrence of KD and dengue [1]." In fact, many patients with $\mathrm{KD}$ have the serological positivity towards dengue [2]. The concurrent occurrence of the two disorders is usually problematic and difficult to diagnose [3, 4]. As noted by Burgner and Harnden, "KD is due to one or more widely distributed infectious agent(s), which evoke an abnormal immunological response in genetically susceptible individuals [5].” Hence, to clarify the exact relationship between dengue and $\mathrm{KD}$ needs advanced immunological study. Indeed, not only dengue but also other viruses, such as respiratory viruses [6], can

Beuy Joob

beuyjoob@hotmail.com

\footnotetext{
Sanitation 1 Medical Academic Center, Bangkok, Thailand

Hainan Medical University, Haikou, China

3 Faculty of Medicine, University of Nis, Nis, Serbia

4 Joseph Ayobabaloal University, Ikeji-Arakeji, Nigeria

5 Surin Rajabhat University, Surin, Thailand

6 Dr DY Patil Medical University, Pune, India
}

concurrently occur with $\mathrm{KD}$. In the present study, it is not clear whether there was complete exclusion of other diseases that might result in occurrence of $\mathrm{KD}$. If it was a case of dengue induced KD, there should have been some periods of pathological immunological induction and the balancing between thrombocytosis or thrombocytopenia should not have occured.

\section{Compliance with Ethical Standards}

Conflict of Interest None.

Source of Funding None.

\section{References}

1. Jagadeesh A, Krishnamurthy S, Mahadevan S. Kawasaki disease in a 2-year-old child with dengue fever. Indian J Pediatr. 2015. doi:10. 1007/s12098-015-1927-8.

2. Sopontammarak S, Promphan W, Roymanee S, Phetpisan S. Positive serology for dengue viral infection in pediatric patients with Kawasaki disease in southern Thailand. Circ J. 2008;72:1492-4.

3. Singh S, Jat KR, Suri D, Ratho RK. Dengue fever and Kawasaki disease: a clinical dilemma. Rheumatol Int. 2009;29:717-9.

4. Mekmullica J, Pancharoen C, Deerojanawong J, Lertsapcharoen P, Thisyakorn U, Thisyakorn C. Concomitant dengue infection and Kawasaki disease in an infant: a case report and literature review. J Med Assoc Thail. 2005;88:436-9.

5. Burgner D, Harnden A. Kawasaki disease: what is the epidemiology telling us about the etiology? Int J Infect Dis. 2005;9:185-94.

6. Turnier JL, Anderson MS, Heizer HR, Jone PN, Glodé MP, Dominguez SR. Concurrent respiratory viruses and Kawasaki disease. Pediatrics. 2015;136:e609-14. 